BULLETIN Bulletin hispanique

HISPANIQUE Université Michel de Montaigne Bordeaux

117-1 | 2015

Les poètes des rhéteurs

\title{
Erratas vitales
}

Antonio Machado y Virgilio en Los complementarios

\section{Francisco García Jurado}

\section{CpenEdition}

Journals

Edición electrónica

URL: https://journals.openedition.org/bulletinhispanique/3871

DOI: 10.4000/bulletinhispanique.3871

ISSN: 1775-3821

Editor

Presses universitaires de Bordeaux

\section{Edición impresa}

Fecha de publicación: 1 junio 2015

Paginación: 301-324

ISBN: 979-10-300-0174-7

ISSN: 0007-4640

Referencia electrónica

Francisco García Jurado, «Erratas vitales», Bulletin hispanique [En línea], 117-1 | 2015, Publicado el 01 junio 2018, consultado el 11 febrero 2022. URL: http://journals.openedition.org/bulletinhispanique/ 3871 ; DOI: https://doi.org/10.4000/bulletinhispanique.3871 


\title{
Erratas vitales: Antonio Machado y Virgilio en Los complementarios
}

\author{
Francisco García Jurado \\ Universidad Complutense. Madrid
}

Entre 1912 dans Los complementarios et 1931 dans l'ébauche de son discours d'entrée à la Real Academia, Antonio Machado reprend plusieurs fois un vers de la première églogue de Virgile qui revêt un indiscutable caractère autobiographique. Analoguement, le bref commentaire que Machado consacre à l'attitude vitale de Virgile dans Los complementarios témoigne d'une possible identification sincère de Machado au poète de Mantoue tel qu'il est présenté dans l'Étude sur Virgile de Sainte-Beuve.

Mots-clés: Virgile, Antonio Machado, Los complementarios, langue latine.

Un verso de la primera égloga de Virgilio aparece utilizado por Antonio Machado con un marcado carácter autobiográfico desde 1912, dentro de Los complementarios, hasta 1931, en el esbozo de su discurso de ingreso en la Real Academia. Asimismo, el sucinto comentario que Machado desarrolla sobre la actitud vital de Virgilio en Los complementarios sugiere una sincera identificación de Machado con el poeta de Mantua, basada en el texto de Sainte-Beuve Étude sur Virgile.

Palabras claves: Virgilio, Antonio Machado, Los complementarios, latín.

From 1912 to 1931, Antonio Machado quoted several times a verse in Latin from Vergil, as an autobiographical feature, first in Los complementarios and finally in the draft of the speech he delivered when joining the Spanish Academy. Besides, the commentary Machado made on Vergil in Los complementarios suggests that he identified to the Roman poet - as Sainte-Beuve sketched him in his Etude sur Virgile.

Keywords: Vergil, Antonio Machado, Los complementarios, Latin language. 
Para Ignacio Rodriguez Alfageme

\title{
1. Virgilio y Machado: Sintonías Literarias ${ }^{1}$
}

En su libro sobre la Generación del 98, Laín Entralgo reflexiona breve, pero intensamente, acerca del tránsito espacial e histórico que va desde el paisaje virgiliano de los Alpes al paisaje madrileño del Guadarrama:

Llega una ocasión en que, por una razón o por otra, tal hombre atiende con más ahínco a la tierra en torno y logra ordenar con la palabra la huella impresa en su espíritu por esa atenta expectación; cuando esto ocurre, un nuevo paisaje nace a la vida histórica. Es, por ejemplo, el momento en que Virgilio pone en dos sobrios, desnudos versos, la emoción de ver oscurecerse la tierra itálica:

Et iam summa procul villarum culmina fumant

maioresque cadunt altis de montibus umbrae

$(\text { Églogas 1, 83-84) })^{2}$

Cabe hallar, por tanto, una sintonía entre el bucolismo de Virgilio y lo que en los escritores del 98 supuso el propio descubrimiento del paisaje ${ }^{3}$. Laín Entralgo acude a los versos que cierran la primera égloga de Virgilio, como muestra consumada de ese arte de reflejar el paisaje y de convertirlo en un estado del ánimo. Veamos el contexto de estos versos virgilianos. El pastor Títiro, ocioso y tranquilo en sus campos, invita a Melibeo, que está de paso y afligido, a que pernocte bajo el cobijo de su hospitalidad ${ }^{4}$ :

\author{
Hic tamen hanc mecum poteras requiescere noctem \\ fronde super viridi: sunt nobis mitia poma, \\ Castaneae molles et pressi copia lactis,
}

1. Este trabajo se integra en el Grupo de Investigación UCM 930136 («Historiografía de la literatura grecolatina en España») y se ha beneficiado de una ayuda UCM/Banco Santander (referencia GR3/14). Mi agradecimiento más sincero a David Castro y Benito Durán por su inestimable ayuda. Al primero de ellos, por facilitarme el texto de Sainte-Beuve sobre Virgilio que traduce Manuel Machado, y al segundo, por darme a conocer y regalarme el facsímil del cuaderno de notas de José Machado. No menos agradecido quedo a la profesora Dolores Rincón, que organizó el acto titulado "Antonio Machado desde la música y la filología. Homenaje», en el paraninfo de la antigua Universidad de Baeza el día 29 de mayo de 2012, donde intervinimos Vicente Cristóbal y yo mismo.

2. Pedro Laín Entralgo, La generación del 98, Madrid, Espasa-Calpe, 1997, p. 32.

3. Para una visión general de esta cuestión, véase Ángel Ruiz Pérez, «Lo bucólico en la literatura del cambio de siglo», en Francisco García Jurado et alii (eds.), La historia de la literatura grecolatina durante la Edad de Plata de la cultura española (1868-1936), Málaga, Analecta Malacitana, 2010, pp. 335-362. De manera más concreta, sobre los clásicos (Epicteto, Marco Aurelio, Virgilio...) y Machado, puede consultarse Rafael Pérez Delgado, Los clásicos en Antonio Machado y contraluz de Unamuno, Madrid, Ediciones de Arte y Bibliofilia, 1975.

4. Para las citas de Virgilio utilizaremos la edición oxoniense de R.A.B. Mynors, P. Vergili Maronis opera, Oxford, Oxford University Press, 1985. 
et iam summa procul villarum culmina fumant

maioresque cadunt altis de montibus umbrae.

(Verg. Ecl. 1, 79-83)

Esta es la versión castellana de los versos citados, según Vicente Cristóbal:

Pero podrías aquí descansar esta noche conmigo

sobre ramaje verde. Tenemos manzanas maduras,

tiernas castańas y gran provisión de leche cuajada.

Que en lontananza ya humean los techos de los caseríos

y prolongadas las sombras descienden de la alta montaña. ${ }^{5}$

Atardeceres como el de esta primera égloga, si bien no son exclusivamente virgilianos, también pueden verse recreados en la poesía del propio Machado más de una vez:

La tarde está muriendo como un hogar humilde que se apaga.

Allá, sobre los montes,

quedan algunas brasas.

Y ese árbol roto en el camino blanco

hace llorar de lástima.

¡Dos ramas en el tronco herido, y una

hoja marchita y negra en cada rama!

¿Lloras?... Entre los álamos de oro,

lejos, la sombra del amor te aguarda.

(«Campo» LXXX [Obras completas I, pp. 482-483]) ${ }^{6}$

La tarde, convertida en sentimiento y subjetividad ${ }^{7}$, no es patrimonio de un solo poeta ni de una única experiencia. Ahí tenemos, por no recurrir más que a poemas esenciales, el final de la égloga primera de Garcilaso ( «la sombra se veía / venir corriendo apriesa / ya por la falda espesa / del altísimo monte») o la propia traducción que Fray Luis hace de la primera égloga ( $Y$ Y ya las sombras caen de las montańas / más largas y convidan al sosiego; / y ya de las aldeas y cabañas / despide por los techos humo el fuego»). Al cabo de los siglos, Machado nos muestra ahora el interior del hogar de donde salía el humo de las altas chimeneas («hogar humilde que se apaga»), el mismo apresuramiento del tiempo («la tarde está muriendo»), la lejanía de las montañas («allá, sobre los montes»), o

5. Virgilio, Bucólicas. Edición bilingüe de Vicente Cristóbal, Madrid, Cátedra, 1996, p. 81.

6. Para la cita de las obras de Machado recurrimos a Antonio Machado, I Poesías completas. Edición crítica de Oreste Macrì con la colaboración de Gaetano Chiappini, Madrid, EspasaCalpe / Fundación Antonio Machado, 1989 (= Obras completas I) y Antonio Machado, II Prosas completas. Edición crítica de Oreste Macrì con la colaboración de Gaetano Chiappini, Madrid, Espasa-Calpe / Fundación Antonio Machado, 1989 (= Obras completas II). La edición más reciente, Antonio Machado, Tutte le poesie e prose scelte, con due saggi introduttivi di Giovanni Caravaggi, traduzioni poetiche di Oreste Macrì (Milán, Mondadori, 2010), no ofrece cambios sustanciales con respecto a nuestro objeto de estudio.

7. Manuel Alvar, «Prólogo» a Antonio Machado, Poesias Completas, Madrid, Espasa Calpe, 1983, pp. 15-19. 
la sombra, que en este caso se convierte en "sombra del amor». Estas sintonías entre poetas de tiempos diversos nos hacen pensar en la tradición clásica no exclusivamente como una actitud culturalista, sino como un afán que responde a profundas vivencias comunes que van más allá de los tiempos. Un momento de relativa y triste calma acontece en la vida de Antonio Machado en el otońo de 1912 cuando llega a Baeza, acaso convertida en uno de esos «lugares donde se calma el dolor», como sugiere el nombre de la napolitana Posilipo, donde la leyenda dice que está precisamente la tumba del propio Virgilio ${ }^{8}$. Cabe seguir estableciendo más sintonías, pues si el amenazante olmo que evoca Virgilio en el segundo libro de su Eneida es la encarnación de una Troya a punto de sucumbir, en especial cuando cae derribado estrepitosamente a manos de los leñadores (Virg. Aen. 2, 624-631), el olmo machadiano, «hendido por el rayo y en su mitad podrido", queda en Soria, al igual que Leonor, como metáfora del dolor y el renacer de la esperanza.

Es precisamente en 1912 cuando Machado pone la primera fecha a lo que terminará siendo un libro misceláneo, rico en reflexiones y apuntes, verdadera cantera literaria, que completará entre 1919 y 1925 . Se trata de un cuaderno concebido para menesteres más prosaicos, como sugiere su misma tapa roja de abrumador sabor administrativo, pero que fue destinado a servir de cobijo a lo que, con el tiempo, conoceremos como Los complementarios ${ }^{9}$. En este libro aparecen varias alusiones a Virgilio que, acaso por su aparente insignificancia y brevedad, no se han considerado todo lo que, en nuestra opinión, merecen. Nos referimos a una cita tomada de un verso de la primera égloga que aparece dos veces dentro del cuaderno y a un elogioso comentario sobre Virgilio al que subsiguen cinco versos del libro VI de la Eneida, ligado a la consideración conjunta que reciben Virgilio y Dante ya desde la primera hoja de Los complementarios. Estas tres referencias, a saber, la cita de la égloga, la admiración por la persona de Virgilio y su libro VI de la Eneida van a articular nuestro trabajo.

8. «Yo busco el Parque Virgiliano que se extiende detrás de la iglesia de Santa Maria de Piedigrotta en Mergellina. Allí están, a los pies de la colina de Posilipo, la cueva de Virgilio, su propia tumba y también la de Leopardi. La galería se excavó en el siglo I a.C. para ir de Nápoles a Pozzuoli y a los Campos Flégreos, la tierra quemada, la tierra de fuego por donde corrían las aguas termales calentadas por el Vesubio. Esta obra de ingeniería se llevó a cabo por la guerra civil en Roma. Según Estrabón, los trabajos fueron dirigidos por el arquitecto romano Lucio Cocceios Auctus. Los romanos se hicieron construir sus villas en este alto promontorio. La mayor de estas mansiones tenía por nombre Pausilypon, "el lugar donde se calma el dolor", pues un bálsamo era la vista virginal de la bahía de Nápoles que ofrecía. Ahora está poblada de casas por doquier. La colina tomó luego como denominación general el mismo nombre.» (César Antonio Molina, Lugares donde se calma el dolor, Barcelona, Destino, 2009, p. 9).

9. El cuaderno, por lo que podemos leer ya en la primera página, comenzó a cobrar forma en 1912, con la llegada de Machado a Baeza, y continuó escribiéndose hasta 1925 en otros lugares, como Madrid. Cf. Domingo Ynduráin, «Introducción» a Antonio Machado, Los complementarios. Transcripción, Madrid, Taurus, 1971, p. 11. Hemos utilizado, asimismo, el facsímil que acompaña a este estudio, además de la edición de Manuel Alvar (Los complementarios, Madrid, Cátedra, 1997), que reordena los fragmentos, y la citada edición crítica de Oreste Macrì (Obras completas II, pp. 1149-1375). 


\title{
2. EXPRESIÓN DE LA EDAD: UN VERSO DE LA PRIMERA ÉGLOGA
}

Dentro del conjunto de las diez Églogas de Virgilio, la primera que podemos leer nos presenta, como ya hemos referido, un diálogo entre dos pastores, Títiro y Melibeo, que declaman sus penas y alegrías. El pastor Títiro, cuya condición es la de liberto, nos cuenta cómo ha recuperado su libertad muy tardíamente, cuando ya su barba caía cada vez más blanca al afeitarse:

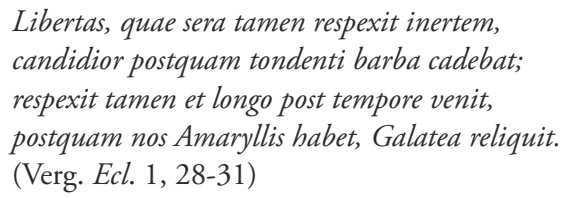

Vicente Cristóbal (op. cit., p. 76) traduce el pasaje de la manera siguiente:

La libertad, que, aun tardía, volvió a mi flaqueza sus ojos, cuando, afeitándome, ya más canosa caía mi barba; ojos volvió, sí, y después de una ausencia tan larga llegose, cuando Amarilis me tiene y dejado me ha Galatea.

Es posible que los niños o jóvenes que durante generaciones han aprendido esta égloga de memoria en la escuela ${ }^{10}$ no hayan entendido el sentido irónico que suponen las cosas cuando llegan a destiempo, es decir, cuando ya nuestra barba está canosa. Sin embargo, una persona de mayor edad sí puede reparar en esta ironía del tiempo, y hasta extraer el propio verso 29 de la égloga para acuñarlo, precisamente, como una cita que dé cuenta de su propia experiencia vital. En todo caso, la primera página del cuaderno de Machado contiene dos citas, una de Virgilio y otra de Dante, y la primera de ellas es, precisamente, este verso, que reproducimos tal como lo hace el propio Machado:

\author{
candidior postquam tondendi (sic) barba cadebat \\ (Obras completas II, p. 1152) ${ }^{11}$ \\ Virgilio. Eglogas
}

10. Dice Ernst Robert Curtius que la Eneida no basta para conocer a Virgilio, pues la influencia de las Églogas ha sido tan grande como la de aquella: «Desde el primer siglo del Imperio hasta la época de Goethe, la enseñanza de la literatura latina comenzaba con la lectura de la primera égloga; no es exagerado afirmar que quien no tenga en la cabeza este poemita no tendrá tampoco la clave de la tradición literaria europea.» (Ernst Robert Curtius, Literatura europea y Edad Media latina (1), México, F.C.E., 1988, p. 273).

11. En el aparato crítico de Macrì se dice: «tondendi. corríjase tondenti» (Obras completas II, p. 1840). Curiosamente, la errata ha pervivido sin excepción en las diferentes ediciones y referencias que se hacen a esta cita machadiana tanto en estudios como en ediciones de Los complementarios. La última vez que la he visto recogida sin advertencia alguna ha sido en José Carlos Mainer, Historia de la literatura española 6. Modernidad y nacionalismo 1900-1939, Madrid, Crítica, 2010, p. 352. 
No es difícil adivinar el tono autobiográfico que esta frase puede adoptar al comienzo del cuaderno de apuntes machadiano, pues se trata de un verso que recuerda a expresiones como "peinar canas». Virgilio, que al componer esta obra tendría unos 28 años, pone en boca del pastor Títiro una manera indirecta de decir su edad en calidad de personaje ficticio, más o menos 45 años. Este uso de la cita por parte de Machado al comienzo del cuaderno puede guardar cierta correspondencia con la propia edad del poeta en 1912, es decir, 37 años. Machado asumió la cita como propia y la fue utilizando a lo largo de su vida en otros lugares de su obra, incluso unos años más tarde dentro del mismo cuaderno de Los complementarios. Pero la cita comporta una singular errata, pues el participio de presente "tondenti», declinado en dativo singular para referirse precisamente a la persona que está hablando («a mí, mientras me afeitaba»), se convierte ahora, y por dos veces, en una extraña forma «tondendi», acaso más redonda desde el punto de vista fonético, si bien a un latinista le hace pensar en una incomprensible forma de gerundio ("tondendum») en caso genitivo ${ }^{12}$. Machado debió de aprender esta cita de memoria, pero la memoria es creativa, hasta el punto de haber forjado en su mente la sonora errata referida. Tan asentada debía de estar la errata que Machado volvió a reproducirla dentro del mismo cuaderno, precisamente al final de un interesante texto que comienza hablando sobre Homero:

Cuando Homero dice la nave hueca, no describe nave alguna, sino que, sencillamente, nos da una definición de la nave, una idea de la nave, que es una visión de la nave y un punto de vista al par, para ver naves, ya se muevan éstas por remo, por vapor o rayos ultravioletas. ¿Está la nave homérica fuera del tiempo y del espacio? Como queráis. Sólo importa a mi propósito hacer constar que todo navegante la reconocerá por suya. Fenicios, griegos, normandos, venecianos, portugueses o espańoles han navegado en esa nave hueca a que alude Homero y en ella seguirán navegando todos los pueblos del planeta. [...]

Y no se tomen estas palabras como precepto de habilidad efectista. Que nuestro mundo interior contenga algunas flores vivas entre muchas flores disecadas, no pasa de ser metáfora de filósofo tan imprecisa como una teoría de poeta. Imprecisa y, en parte, errónea; porque nada en nuestra psique recuerda

12. "Tondendi» recuerda, por ejemplo, a la forma de gerundio en genitivo «amandi» que da lugar al conocido título del Ars amandi ("Arte de amar») de Ovidio. El problema viene dado porque en el texto virgiliano una forma como «tondendi» no tiene sentido. Cuando a finales del mes de mayo de 2009 acudí al congreso de la Sociedad de Estudios Latinos que se celebraba en Baeza, visité una tarde el antiguo claustro de la universidad, anejo al instituto Santísima Trinidad, precisamente donde está la clase que rinde emotivo homenaje al poeta Antonio Machado, en recuerdo de su paso como profesor de francés. Aquella tarde recordé el cuaderno de notas de Los complementarios, con su cita inicial del verso virgiliano. Sin embargo, algo fallaba en mi recuerdo de este verso, pues mi memoria no me traía la forma «tondenti», sino «tondendi». Mientras pensaba todo esto, seguía bullendo en mi cabeza la incorrecta forma "tondendi», y no me explicaba bien por qué. Lo que la gramática corregía lo desleía el corazón al acudir a mi mente. Mi sorpresa fue cuando, al regresar a Madrid, pude comprobar en el facsímil de la obra que la errata estaba en el mismo Machado, que seguramente escribió el verso de memoria y tal como le sonaba. 
a un herbario. Pero aceptemos su parte de verdad. No pretendamos ser más originales de lo que somos, ni demasiado niños candidior postquam tondendi (sic) barba cadebat. AM.

(“Sobre poesía", en Los complementarios, 114 R - 115 R [Obras completas II, pp. 1278-1279])

En este caso vemos, además, cómo la cita se incrusta dentro de la propia frase castellana, en un intento un tanto pedantesco de rematar el párrafo en lengua latina. El texto en cuestión ha debido de ser escrito hacia 1915, por lo que han transcurrido unos tres años desde el uso inicial de la cita, aunque podemos ver cómo sigue perviviendo la errata. La errata da idea del conocimiento rudimentario que Machado debía de tener de la gramática latina, si bien ello no es óbice para que comprenda el sentido del verso virgiliano y lo utilice con propiedad. Muestra de este conocimiento es también la posibilidad de encontrar algún verso machadiano que parece estar inspirado en la misma cita virgiliana. Así lo vemos sin necesidad de salir de Los complementarios, en la parte correspondiente a su Cancionero apócrifo, uno de cuyos sonetos, el titulado «Guerra de amor» (1924), compuesto por su heterónimo Abel Martín, comienza de la manera siguiente:

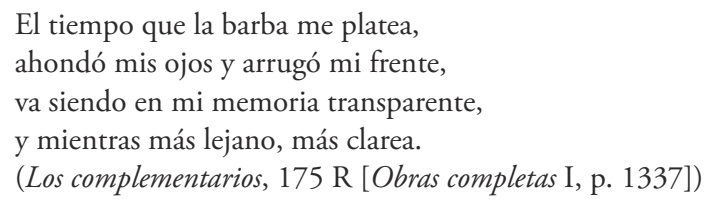

Esa barba plateada por el tiempo sintoniza bien con el verso citado de la égloga, y la idea dinámica que sugiere el adjetivo en grado comparativo, «candidion», bien podría estar recogida en "más clarea». No obstante, no nos encontramos ante un caso de mera servidumbre poética de Machado con respecto a Virgilio. Ya fuera del cuaderno, es posible hallar de nuevo la cita virgiliana cuando encabeza un poema de marcado carácter personal, afín al anterior, donde se nos presenta al poeta ante su propia imagen envejecida:

Candidior postquam tondenti barba cadebat

Virgilio: Égloga I

¿Cúya es esta frente? ¿Cúyo

este mentón azulado?

¿Cúya esta boca sumida,

y estos ojos fatigados

de la letra diminuta

y de los montes lejanos?

Siempre mira el hombre al hombre

Con piedad de su retrato.

Madrid, junio de 1922

(«Simpatías», CCXXI [Obras completas I, p. 795] ${ }^{13}$ )

13. Por lo que podemos ver en el aparato crítico de Macrì (Obras completas I, p. 795), el verso 
Como vemos, desde 1912 hasta 1922 la cita sigue acompañando a Machado en sus composiciones. Al tratarse ahora de una edición impresa, no tenemos constancia de que la errata de «tondendi», que ya nos parece tan propiamente machadiana, haya sido corregida precisamente por una tercera mano o por el propio Machado, quien, según el testimonio de su hermano José, sentía horror ante las erratas ${ }^{14}$. Sin embargo, la historia de las erratas no termina aquí. Aunque la cita vuelve a aparecer con la forma correcta «tondenti» en un nuevo lugar, encontramos una inesperada modificación en la forma del imperfecto "cadebat», que va a aparecer reescrito como «cadet». Así lo vemos en un artículo titulado "El simbolismo» (publicado en La voz de Soria el 8 de septiembre de 1922). El párrafo no es más que una reescritura del que antes hemos leído en Los complementarios:

Y no se piensen estas palabras como precepto de habilidad técnica. Que nuestro mundo interior contenga algunas flores vivas entre infinitas flores disecadas no pasa de ser una metáfora de filósofo, tan imprecisa como una teoría de poeta. Imprecisa y, en parte, errónea, porque nada hay en nuestra «psique» que recuerde un herbario. Pero reconozcamos su parte de verdad. No pretendemos ser más originales de lo que somos ni demasiado niños.

"Candidior postquam tondenti barba cadet (sic)"

(Obras completas II, p. 1638) ${ }^{15}$

Cabría pensar que se trata de un mero error, pero la forma «cadet» vuelve a aparecer dentro del Proyecto del discurso de ingreso en la Academia de la lengua, redactado en 1931:

Es la edad en que, fatalmente, desconfiamos de merecer todo honor y toda ventura que no esperábamos. Así, el hombre que en plena juventud no logró inquietar demasiado el corazón femenino, y ya en su madurez vio claro que los caminos de Don Juan no eran los suyos, se siente algo desconcertado y perplejo si, «candidior postquam tondenti barba cadet (sic)», alguna bella dama le brinda sus favores. Y pongo este ejemplo, aparentemente inadecuado, para demostraros que no es menosprecio del honor que no se espera o de la dicha inopinada la causa de nuestro desconcierto y perplejidad porque ¿quién habrá que desdeñe el amor aunque le llegue cuando el sueńo perdurable comienza a enturbiarle los ojos?

(Obras completas II, p. 1778)

Por lo que creemos adivinar, Machado quiso cambiar la forma de pretérito imperfecto de «cadebat» («caía») por un atemporal presente, a fin de ensartar

latino sí aparece aquí citado correctamente.

14. «De su verdadero horror a las erratas. Era tal el disgusto que le producían las erratas en sus libros, que por encima de todo pedía siempre, en sus ediciones todas las pruebas que fueran necesarias. No daba la aprobación hasta estar seguro que estaban todas corregidas.» (José Machado, Últimas soledades del poeta Antonio Machado. Transcripción, Madrid, Sociedad estatal de conmemoraciones culturales, 2008, p. 44).

15. Véase también Antonio Machado, Antología comentada (Poesía y prosa). Edición de Francisco Caudet, Madrid, Ediciones de la Torre, 1999, p. 96. 
mejor la cita en su nuevo contexto, pero de nuevo se originó un traspié gramatical, ya que la forma de presente del verbo «cado» es «cadit». No es difícil ser presa de la confusión si equiparamos, sin más, la correspondiente forma verbal espańola «cae» con la latina «cadet» ${ }^{16}$. En realidad, más que de una errata cabe hablar de un verdadero error gramatical. Como podemos ver, en los casos mencionados la cita viene referida a la edad del poeta, a su etapa de madurez vital, enfilando ya la vejez. Probablemente, Machado aprendió la cita de memoria, al sentirse especialmente identificado con ella. Primero la utilizó como una cita exenta, pero luego fue intentando insertarla en los textos que componía, para lo que creyó oportuno modificar la forma verbal originaria. Estos traspiés con el latín dan idea de un precario conocimiento gramatical que el propio Machado reconoce alguna $\mathrm{vez}^{17}$, como en la curiosa y conocida carta que envía a Julio Cejador en 1917, entonces catedrático de latín en la Universidad de Madrid, poco antes de examinarse con él ${ }^{18}$ :

Querido y admirado maestro:

El próximo lunes compareceré ante V. con harto rubor y como reo de lengua latina. Bien hubiera deseado asistir a sus clases, aprovechando la ocasión tal vez única, de aprender el habla de Virgilio; pero mi condición de catedrático rural me tiene en Baeza, como antes en Soria, y a muchas leguas de su cátedra. Deseando allegar medios oficiales para mejorar de fortuna, emprendí los estudios de Filosofía, y llevo, con la de V., cinco asignaturas, entre ellas el griego. Reducido a mis propios recursos, con la mezquina base del latín aprendido hace treinta ańos, gracias a su buen método he traducido la Epistola de Horacio y cuanto tiene V. de Virgilio, en su texto, y algo, también, de Salustio y de Cicerón, abarcando cuanto más he podido, y, seguramente, apretando poco. Pero ¿para qué decirle lo que ha de ver? Sólo pretendo declararle mi buen deseo, para recomendarme a su benevolencia y para que no vea en mí el fresco capaz de sonrojar a los amigos, ni tampoco al petulante poeta modernista, pues después de traducir, aunque a trancas y barrancas, versos de Virgilio, el "cur ego salutor poeta” del maestro Horacio es cosa que me digo a mí mismo. Vea V. en mí un caso de anacronismo escolar, y a un viejo desmemoriado estudiantón que de todas sus bondades necesita. [...]

(Obras completas II, p. 1597) $^{19}$

Machado debió de utilizar hacia 1917 una de las más conocidas obras didácticas de Julio Cejador, su Nuevo método teórico-práctico para aprender

16. La forma «cadet» existe en latín, pero es un futuro imperfecto que en el texto de Machado no tiene sentido alguno.

17. La siguiente afirmación que hace Ian Gibson sobre el conocimiento de latín en Machado no tiene fundamento alguno: «Por lo que nos dice en Los complementarios del poeta de la Eneida, parece ser que también logró un meritorio dominio del latín.» (Ian Gibson, Ligero de equipaje. La vida de Antonio Machado, Madrid, Aguilar, 2006, p. 316).

18. En el Archivo Histórico Nacional puede consultarse el expediente académico de Antonio Machado (UNIVERSIDADES, 6647, EXP. 12) correspondiente a los años 1915-1919.

19. Publicada primeramente en Rafael Santos Torroella, «Don Antonio Machado se examina. Una carta inédita", Insula, 158, enero 1960 (apud José Luis Cano, Antonio Machado, Barcelona, Salvat, 1986, pp. 125-126). 
la lengua latina (1907-1908) ${ }^{20}$, que mereció una elogiosa reseña de su otrora discípulo José Ortega y Gasset ${ }^{21}$. Ignacio Rodríguez Alfageme ha cotejado lo que cuenta Machado en la carta con los textos contenidos en el método de Cejador:

[...] tomo 1, Cicerón, de senectute, seguido de algunas cartas del mismo autor; tomo III, Salustio, de Conj. Cat., cap. I-XXXIII; Horacio, Epistula ad Pisones; Virgilio, Eccl. IV, y de la Eneida los versos 1-156 del libro primero y del libro sexto los versos 268-477 y 638-678. Los otros tomos están dedicados a la gramática y a una traducción literal de los textos que se incluyen. Dejando de lado el cambio de orden existente en la carta de Machado, que muestra claramente las preferencias de don Antonio, los paralelos que hemos indicado en su poesía señalan que ha ido más lejos en sus lecturas de Horacio de los límites marcados por el método de J. Cejador. ${ }^{22}$

Machado debió de estudiar estos textos por su cuenta, tras haber transcurrido muchos años desde su no muy fructífero paso por el bachillerato ${ }^{23}$, primero en el Instituto San Isidro (1889-1890) ${ }^{24}$ y luego en el del Cardenal Cisneros $(1890-1891)^{25}$. En todo caso, Machado tuvo que abandonar sus estudios antes de que se produjera la renovación de la enseñanza del latín a comienzos del siglo XX, de la mano de profesores como Vicente García de Diego o el propio Cejador ${ }^{26}$.

En definitiva, el uso que hace Machado de un verso de la primera égloga de Virgilio va más allá de un mero lugar común, aparentemente superficial. Una mirada más detenida, propia de una retórica de la cita, nos da a entender que este verso no está elegido al azar, que ha sido citado de memoria (de ahí la errata de "tondendi»), que ha sido objeto posteriormente de una incorrecta modificación (de «cadebat» a "cadet») y que debe entenderse en un sentido

20. Julio Cejador y Frauca, Nuevo método teórico-práctico para aprender la lengua latina. Primer curso, Palencia, Imp. y lib. De Gutiérrez y Herrero, 1907 y Nuevo método teórico-práctico para aprender la lengua latina. Segundo curso, Palencia, Imp. y lib. De Gutiérrez y Herrero, 1908. El ejemplar correspondiente al segundo curso puede consultarse virtualmente en la siguiente dirección electrónica [consultada el 22 de mayo de 2012]:

http://archive.org/stream/nuevomtodoteori01 fraugoog\#page/n121/mode/2up

21. Véase José Ortega y Gasset, «Sobre los estudios clásicos (El Imparcial, 28 de octubre de 1907)», en Misión del bibliotecario, Madrid, Revista de Occidente, 1967, pp. 21-27).

22. Ignacio Rodríguez Alfageme, «Horacio y Machado», EClás 88, 1984, pp. 467-472, esp. 470-471.

23. José Luis Cano, op. cit., pp. 28-29.

24. En el actual Museo del Instituto San Isidro de Madrid puede verse expuesta la hoja de calificaciones de Machado, con el correspondiente suspenso en latín. El catedrático de latín era Eugenio Méndez Caballero. ("CEIMES. Ciencia y Educación en los Institutos Madrileños de Enseñanza Secundaria (1837-1936)», disponible en la siguiente dirección electrónica [constultada el 22 de mayo de 2012]: http://www.ceimes.es/).

25. El catedrático de la asignatura por aquel entonces era el latinista Francisco A. Commelerán Gómez.

26. Javier Espino Martín, «Vicente García de Diego y la renovación de la gramática latina», en Francisco García Jurado et alii (eds.), op. cit., 2010, pp. 113-136. 
autobiográfico al menos desde 1912. Si Jorge Luis Borges hizo del consciente error de las citas latinas un recurso estilístico ${ }^{27}$, en el caso de Machado las erratas, inconscientes, delatan un conocimiento precario de la gramática latina, fruto de un mal aprendizaje que, sin embargo, no va a ser óbice para que el poeta exprese su franca admiración por Virgilio también dentro del cuaderno de notas de Los complementarios.

\section{Si me obligaran a ElEgir un POETA}

Ya adentrados en las páginas del cuaderno, encontramos un sorprendente y emotivo comentario acerca de Virgilio al que subsiguen cinco versos del libro VI de la Eneida:

Virgilio. Si me obligaran a elegir un poeta, elegiría a Virgilio. ¿Por sus Églogas? No. ¿¿Por sus Geórgicas? No. ¿’Por su Eneida? No.

$1^{\circ}$ Porque dio asilo en sus poemas a muchos versos bellos de otros poetas, sin tomarse el trabajo de desfigurarlos.

$2^{\circ}$ Porque quiso destruir su Eneida ¡tan maravillosa!

$3^{\circ}$ Por su gran amor a la naturaleza.

$4^{\circ}$ Por su gran amor a los libros.

Ibant obscuri sola sub nocte per umbram,

perque domos Ditis vacuas, et inania regna;

quale per incertam lunam sub luce maligna

est iter in silvis, ubi caelum condidit umbra

Jupiter, et rebus nox abstulit atra colorem.

Eneida $=$ Canto VI

(Los Complementarios, 14R [Obras completas II, p. 1169])

El texto, redactado en 1914, puede parecer, a primera vista, ingenuo, pero presupone la conciencia por parte de Machado de una arraigada tradición crítica e historiográfica. No debe olvidarse que una famosa novela publicada en 1884, Al revés, de Joris Karl Huysmans, había desarrollado una acerba crítica contra Virgilio:

Entre otros, el dulce Virgilio, al que los pedantes apodan "el cisne de Mantua”, sin duda porque no nació en esta ciudad, le parecía uno de los más terribles maestros de escuela, uno de los más siniestros lateros que la antigüedad haya producido nunca. Sus pastores lavados y emperifollados, tirándose por turno a la cabeza pucheros llenos de versos sentenciosos y helados; su Orfeo, a quien compara con un ruiseñor lacrimoso; su Aristeo, que lloriquea a causa de las abejas, y su Eneas, ese personaje indeciso y alfeñicado que se pasea, cual una sombra chinesca, con gestos de madera, detrás del transparente mal sujeto y mal engrasado del poema, le exasperaban. Habría aceptado las fastidiosas faramallas

27. «La amistad silenciosa de la luna / (cito mal a Virgilio) te acompaña» (cf. Francisco García Jurado, "Todas las cosas que merecen lágrimas". Borges, traductor de Virgilio», Studi ispanici 35, 2010, p. 301 y «Borges y los inicios de la seducción virgiliana. Una hermenéutica de la nostalgia», Bulletin of Hispanic Studies [Univ. Glasgow] 92, 2015). 
que esos monigotes cambian entre sí en un rincón; habría aceptado hasta los impúdicos hurtos hechos a Homero, a Teócrito, a Enio y a Lucrecio; el simple robo que nos ha revelado Macrobio del segundo canto de la Eneida, casi copiado palabra tras palabra de un poema de Pisandro; toda la inenarrable vacuidad, en fin, de ese montón de cantos. ${ }^{28}$

Eça de Queiroz, en su novela póstuma titulada La ciudady las sierras, escribió lo que Alfonso Reyes calificó de novela «al revés» del Al revés de Huysmans, y donde no falta incluso una recreación bucólica de los versos del poeta, precisamente de la primera égloga. La novela, que apareció impresa por primera vez en 1902, nos cuenta la peripecia de un joven aristócrata, Jacinto, que vive hastiado de su vida decadente en París y decide volver a sus tierras portuguesas. Una vez allí, al tiempo que emprende una vida bucólica, no dejará por ello de tomar conciencia de los problemas de su gente. La obra no está, por tanto, exenta de aspectos que nos recuerdan al regeneracionismo hispano. En otro $\operatorname{lugar}^{29}$, he estudiado la circunstancia de que el poeta Virgilio, denostado por Huysmans como paradigma del canon académico, se convirtiera para Eça de Queiroz en una plácida y amena lectura. Hay, de hecho, un momento esencial en que Eça de Queiroz recurre a los versos de Virgilio para insertarlos en la paz del nuevo ambiente rural:

Sobre una de esas tablas descansaban dos espingardas; en las otras aguardaban, diseminados, como los primeros doctores llegados a un concilio, algunos nobilísimos volúmenes, un Plutarco, un Virgilio, la Odisea, el Manual de Epicteto y las Crónicas de Froissart. Después, en ordenadas hileras, sillas de enea, muy nuevas y lustrosas. Y en un rincón, un mueble para bastones.

Todo resplandecía de orden y limpieza. Los postigos entornados protegían contra el sol, que de aquel lado caía ardientemente escaldando los ventanales de piedra. Olían los claveles. Del suelo, lavado con agua, emanaba en la tamizada penumbra una blanda frescura. Ningún rumor turbaba los campos ni la casa. Tormes dormía bajo el esplendor de la mańana santa. Y, vencido por aquella consoladora quietud de convento rural, acabé por tenderme en un sillón de junco junto a la mesa y abrir lánguidamente un tomo de Virgilio, murmurando, sin más que apropiar ligeramente el dulce verso que leí primero:

Fortunate Jacinthe! Hic, inter arva nota

et fontis sacros, frigus captabis opacum... ${ }^{30}$

¡Afortunado Jacinto, en verdad! ¡Ahora, entre los campos, que son tuyos, y las fuentes que te son sagradas, encuentras finalmente sombra y paz!

28. Joris Karl Huysmans, Al revés (À rebours). Prólogo de Vicente Blasco Ibáñez. Versión española de Germán Gómez de la Mata, Valencia, Prometeo, ca. 1919, p. 76.

29. Francisco García Jurado, «Virgilio entre los modernos. Un singular capítulo de la lectura de las Geórgicas en Joris-Karl Huysmans, José María Eça de Queiroz y Cristóbal Serra (ensayo de Literatura Comparada)", CFC (Lat) 16, 1999, pp. 45-75. Véase también Francisco García Jurado, "A cidade e as serras de Eça de Queiroz, ou "esse adorável Virgílio". Do bucolismo á palingenesia», Estudos Ibero-Americanos, PUCRS, 40/2, jul-dez. 2014, pp. 304-305.

30. Se trata de una cita de Verg. Ecl. 1, 51-52, donde se ha cambiado «senex» por "Jacinthe» y «flumina» por «arva», sin tener en cuenta la métrica del hexámetro: «fortunate senex, hic inter flumina nota / et fontis sacros frigus captabis opacum». 
Leí todavía otros versos. Y, con el cansancio de las dos horas de camino y de calor desde Guiaes, acabé por dormirme irreverentemente sobre el divino bucólico. ${ }^{31}$

Esta circunstancia, pese a su aparente intranscendencia, supone toda una reconsideración del autor clásico. Por ello, la anécdota de semejante escena bucólica responde a un complejo trasfondo. Tras siglos de tradición imitativa, los autores que llamamos clásicos se convirtieron a partir del romanticismo en metas que superar. El decadentismo, por su parte, intentó invertir lo que la estética académica proponía como canónico, reaccionando, precisamente, con hastío -el «spleen» o la melancolía literaria ${ }^{32}$ - ante lo aceptado por la sociedad. Sin embargo, esta actitud finisecular da un nuevo giro a comienzos del siglo XX, y Virgilio pasa a ser objeto de renovado interés estético. Por su parte, Machado no es ajeno a esta renacida admiración por Virgilio cuando expresa un juicio de valor que no concierne tanto a alguna de las tres obras capitales de Virgilio, sino a la actitud que el poeta como tal muestra hacia la propia literatura. No en vano, el texto de Machado debe de estar motivado por una lectura concreta que el poeta estaba haciendo en este momento. Además de alguna gramática, como el ya citado Nuevo método teórico práctico para aprender la lengua latina de Julio Cejador, o incluso alguno de los manuales de literatura latina a los que pudiera tener acceso nuestro autor ${ }^{33}$, es posible que Antonio Machado estuviera leyendo una traducción de las obras de Virgilio que su hermano Manuel había preparado para la parisina editorial Garnier a partir de un texto francés ${ }^{34}$. Esta traducción contenía, además, un estudio previo sobre Virgilio compuesto por uno de los más afamados y polémicos críticos literarios de la Francia del siglo XIX: Charles Augustin Sainte-Beuve (1804-1869). El texto de Sainte-Beuve pertenece a las conferencias que el autor había impartido en el Colegio de Francia en $1855^{35}$. Sabida es la preocupación que SainteBeuve tenía por la biografía de los autores, tanto que a menudo, cuando diserta acerca de Virgilio, parece que va más allá de los pocos datos comprobables que tenemos sobre el poeta y trasciende a una suerte de ficción biográfica repleta de atrevidos juicios de valor. Tras indagar en el asunto, estamos en condiciones

31. José María Eça de Queiroz, La ciudad y las sierras. Trad. de Eduardo Marquina, Barcelona, Bruguera, 1984, pp. 160-161.

32. Para el concepto de «spleen», que podría entenderse como «melancolía vital», «hastío» o «taedium vitae», véase Guillermo Díaz Plaja, Tratado de las melancolías españolas (Madrid, Sala, 1975), especialmente las páginas dedicadas a la «Melancolía modernista» (pp. 265-284).

33. Precisamente, en 1914 aparece la primera edición del Epitome de literatura latina de Julio Cejador (Madrid, Imprenta de la «Revista de Archivos, bibliotecas y museos», 1914).

34. Obras de Virgilio. Estudio crítico por Sainte-Beuve. Versión castellana de Manuel Machado. Bucólicas-Geórgicas-Eneida, Paris, Casa Ed. Garnier Hermanos, [s.a.] [depósito legal 1914]. Para las circunstancias de este libro véase David Castro de Castro, «Los clásicos grecolatinos en la bohemia», en Francisco García Jurado et alii (eds.), op. cit., pp. 232-236.

35. El curso como tal fue publicado, y se tradujo al español: Sainte-Beuve, Estudio sobre Virgilio. Traducción de Luis de Terán, profesor de la sección de literatura del Ateneo de Madrid, Madrid, La Espańa Moderna, ca. 1908. 
de afirmar que Antonio Machado partió de los juicios críticos de Sainte-Beuve, si bien traducidos por su hermano Manuel, al redactar la nota virgiliana de Los complementarios. Para empezar, esta preferencia que muestra Machado por la figura vital de Virgilio por encima de sus obras concuerda con el propio planteamiento literario de Sainte-Beuve, que ve la obra literaria de un autor como el claro reflejo de su vida ${ }^{36}$. Los cuatro breves comentarios que siguen enumerados contemplan sendas facetas fundamentales que aparecen en la propia obra crítica de Sainte-Beuve:

a) La primera («Porque dio asilo en sus poemas a muchos versos bellos de otros poetas, sin tomarse el trabajo de desfigurarlos») concierne a la cuestión, tan propia de la estética romántica, de la originalidad del poeta. Sainte-Beuve sale al paso de tales asertos y defiende precisamente esta labor hospitalaria de recoger versos ajenos (las cursivas son mías):

Sabe muy bien que hace un alto honor a estos poetas un tanto rústicos, al coger de ellos la parte mejor y darles un asilo. Si tienen algunos hermosos versos diseminados entre sus obras, como errantes, Virgilio los coloca entre los suyos y los aloja en su palacio de mármol y en lugar preeminente. ¡Por esto es por lo que han llegado a ser inmortales! Y por lo que le deben gratitud en lugar de censura.

(Sainte-Beuve, apud Manuel Machado, op. cit., p. 55) ${ }^{37}$

El hecho de «no desfigurar» los versos ajenos, en especial los de los poetas latinos, es, según Sainte-Beuve, una manera de rendir homenaje a los poetas a los que copiaba. En este punto, podemos preguntarnos si el propio Machado no ha dado también asilo al verso de la primera égloga de Virgilio en su propia obra. De esta forma, Machado se aleja, al igual que Sainte-Beuve, del extendido juicio de que Virgilio sea un plagiario para elogiar, precisamente, esta faceta con la bella metáfora de dar asilo a versos ajenos.

b) En segundo lugar, la nota biográfica («Porque quiso destruir su Eneida ¡tan maravillosa!») concierne al viejo problema, ya recogido por los testimonios de las Vitae Vergilianae, de la intención que tuvo el poeta de quemar su poema épico, donde, más allá del hecho en sí, se nos escapa la motivación que empujó al poeta ${ }^{38}$. Sainte-Beuve nos habla del siguiente modo acerca de esta circunstancia:

36. «Toute la biographie intime et morale de Virgile est dans ces paroles et dans ce sentiment» (Sainte-Beuve, Étude sur Virgile suivie d'une étude sur Quintus de Smyrne, deuxième édition, Paris, Michel Lévy Fréres, éditeurs, 1870, p. 36).

37. Este es el texto original en francés: «Il sait bien qu'il fait honneur à ces vieux poëtes italiotes et tout pleins de rusticité en leur prenant ce quills ont de bon et en y donnant asile. S'il y a un beau vers perdu quelque part chez eux et comme tombé de leurs ouvres ou errant, il le place chez lui et le loge dans son palais de marbre, en un lieu éclairé. Voilà leur vers devenu immortel! Ils nont qu’à le remercier et non à se plaindre.» (Sainte-Beuve, op. cit., p. 96).

38. Véase José Luis Vidal, "Por qué Virgilio quería quemar la Eneida..., si es que quería», publicado en HVMANITAS in honorem Antonio Fontán, Madrid, Gredos, 1992, pp. 479-484. En este trabajo se repasa la cuestión desde los testimonios positivos procedentes de las Vitae Vergilianae hasta la interpretación puramente hermenéutica del novelista Hermann Broch en su obra titulada La muerte de Virgilio. 
No era dueńo de ocultar y destruir su Eneida, a su antojo, como parece en efecto hubo de pensarlo en un momento de desesperación; la obra pertenecía ya al mundo.

(Sainte-Beuve, apud Manuel Machado, op. cit., p. 31$)^{39}$

Es notable observar cómo el propio Antonio Machado recurre a la literalidad de la nota («destruir su Eneidd») para construir el apunte.

c) El tercer apunte («Por su gran amor a la naturaleza»), responde a un asunto crucial de la estética decadente, precisamente cuando ésta rompió con la idea de que el arte fuera una imitación de la naturaleza ${ }^{40}$, y merced al cual Huysmans consideró a Virgilio como un poeta doblemente negativo, ya que era paradigma del clasicismo y cantor de las cosas del campo. Tal amor se deriva, sobre todo, del tratamiento que hace del campo en sus Geórgicas. Sainte-Beuve insiste muy especialmente en este amor a la naturaleza:

Tenía amor al campo. ¿Quién lo dudaría? En él se crió y de él sacó sus primeras impresiones, sus primeros placeres; consagró los juegos y las rústicas tareas en sus primeros estudios, dedicándoles después sus más perfectos cuadros.

(Sainte-Beuve, apud Manuel Machado, op. cit., p. 51) ${ }^{41}$

Podemos comprobar que Antonio Machado habla de «amor a la naturaleza», mientras que Manuel traduce el texto de Sainte-Beuve como "amor al campo». Sin embargo, un poco más adelante, encontramos la expresión «amar directo a la naturaleza» junto con el rasgo que, probablemente, es el más definitorio de Sainte-Beuve, el del amor a los libros.

d) Entramos así en la cuarta y última apreciación de Antonio Machado («Por su gran amor a los libros»), que se corresponde con el siguiente texto donde se nos coloca ante un poeta que es también lector y amante de los libros, al igual que lo es de la naturaleza, sin fisuras entre uno y otro aspecto:

Une Virgilio el amar directo a la naturaleza y a los paisajes, el amor a los libros, inclinación que no suele ser frecuente entre los que sienten tan vivamente la realidad de las cosas; él conserva de su primera educación, la apasionada admiración a los antiguos autores y poetas, rasgo característico de los poetas

39. "Il n'était plus maître d'étouffer et d'anéantir son Enéide quand il l'aurait voulu, et comme il paraît bien qu'en effet, dans une heure de désespoir, il y a sérieusement songé: elle appartenait désormais au monde.» (Sainte-Beuve, op. cit., p. 67).

40. Véase Hans Robert Jauss, «El arte como anti-naturaleza. A propósito del cambio de orientación estética después de 1789», en Darío Villanueva (comp.), Avances en Teoría de la Literatura, Santiago de Compostela, Universidade, 1994, pp. 117-148.

41. "Il a l'amour de la nature, de la campagne. Qui en douterait? Il y a été nourri, il y a puisé ses premières impressions, ses premiers plaisirs; il a consacré aux jeux ou aux travaux rustiques ses premières études, comme ensuite il leur a voué ses plus parfaits tableaux.» (Sainte-Beuve, op. cit., p. 92). 
cultos y estudiosos de la segunda edad. Tenía el culto de los grandes hombres y escritores que le habían precedido, de igual modo que lo sentía Cicerón.

(Sainte-Beuve, apud Manuel Machado, op. cit., p. 53) ${ }^{42}$

Repetimos que este es el rasgo más característico de Sainte-Beuve, acaso por su aparente obviedad, si bien se trata de un rasgo que deriva en la adopción que hace Virgilio de los textos ajenos y que nos llevaría de vuelta a la primera apreciación de Machado. En suma, hay en esta admiración tan sincera por la actitud vital de Virgilio otro aspecto clave, como la propia identificación del poeta Machado con el poeta de Mantua. Parece claro que Antonio Machado llegó a leer a Sainte-Beuve en la propia versión de su hermano Manuel, y cabe imaginar cómo se llegaría a identificar con el egregio retrato que el crítico francés había hecho del poeta latino. Por estas casualidades que sólo los grandes poetas suelen brindarnos, cuando otro hermano de Machado, José, redactó ya en el exilio americano, y tras la muerte de Antonio, las cuartillas que llevan el título de Últimas soledades del poeta Antonio Machado ${ }^{43}$, algunas de las notas recuerdan mucho a las observaciones que el propio Machado había hecho ya de Virgilio, en especial estas dos:

Su gran amor a la naturaleza

Fue toda su vida un amante de la naturaleza. Daba constantes y largas caminatas por el campo. Ya lo dice: "Mis aficiones son pasear y leer..."

Y mostraba marcada preferencia por los libros de filosofía.

(José Machado, op. cit., p. 23)

Su afición a los libros

Tuvo desde su infancia una afición a la lectura extraordinaria. Hasta el punto [de] que iba a la Biblioteca Nacional todos los días. Allí se pasaba enfrascado en la lectura horas y horas prefiriéndolo, muy mucho, a todo otro género de distracciones más en consonancia con su edad.

Esta afición naciente adquirió con el tiempo tal desarrollo que todo le parecía poco para gastárselo en los libros y en la medida de sus recursos económicos iba adquiriendo todo lo que podía.

(José Machado, op. cit., p. 47)

No en vano, en el libro que el propio José Machado publicó en 1957 con el título de Últimas soledades del poeta se hace referencia al texto de Sainte-Beuve traducido por Manuel Machado:

Recuerdo que el admirable estudio del famoso crítico francés Sainte-Beuve, que precede a las Obras Completas de Virgilio, traducidas del latín al francés, nos cuenta cómo el famoso autor de La Eneida había sido muy criticado y hasta en

42. «En même temps que Virgile aime directement la nature et les paysages, il y joint ce que n'ont pas toujours ceux qui les sentent si vivement, il aime les livres; il tient de son éducation première une admiration passionnée des anciens auteurs et des grands poètes: trait distinctif de ces poètes cultivés et studieux du second âge. Il a le culte de tout grand homme, de tout grand écrivain qui a précédé, comme l'avait et comme l'a souvent rendu avec tant de ferveur Cicéron.» (Sainte-Beuve, op. cit., p. 94).

43. José Machado, op. cit. 
alguna ocasión tachado de "plagiario". A lo que según parece contestaba el poeta aludido que cuando se encontraba con algo coincidente con su pensamiento, dicho ya por alguien de una manera lapidaria, no vacilaba en adoptarlo, pensando modestamente en este caso que él no alcanzaría a decirlo mejor.

El solo hecho de saber elegir lo mejor, en los cantos ajenos, revela el más alto espíritu y una comprensión máxima que en nada aminora una tan egregia figura en la poesía de la magnitud de Virgilio, como lo demuestran sus cantos admirables. ${ }^{44}$

\section{Ibant obscuri: Virgilio, Caronte, la Sibila y Dante}

Finalmente, tras esta exaltación de la actitud vital de Virgilio, Machado nos ofrece una muestra granada de cinco de sus versos, tomados precisamente del libro sexto de la Eneida (Aen. 6, 268-272). Volvemos a reproducirlos tal como aparecen copiados en el cuaderno:
Ibant obscuri sola sub nocte per umbram, perque domos Ditis vacuas, et inania regna; quale per incertam lunam sub luce maligna est iter in silvis, ubi caelum condidit umbra Jupiter, et rebus nox abstulit atra colorem. Eneida $=$ Canto VI (Los Complementarios, 14R [Obras completas II, p. 1169])

Los versos responden esta vez a una copia fiel y no tanto a un ejercicio de la memoria, como ocurría con el verso de la primera égloga. Se trata, precisamente, de los versos que nos describen a Eneas y la Sibila de Cumas descendiendo a los infiernos, y que Espinosa Pólit traduce de la manera siguiente:
Oscuros en la noche solitaria
cruzaban entre sombras la vacía
mansión de Dite, sus desiertos reinos,
como senda de bosque en la que esparce
amortiguada la luz la luna incierta
en el cielo invadido de penumbra,
cuando la noche el mundo descolora. ${ }^{45}$

Es probable que para copiar tales versos Machado utilizara una antología de textos latinos, en todo caso una edición escolar. Así lo delata la aparición del nombre de "Jupiten» escrito de esa manera y no «uppiten». En un principio, consideramos que lo más probable era que el texto latino hubiera sido copiado de la antología de textos que Julio Cejador reproduce en el libro segundo de su Nuevo método ${ }^{46}$, pero un simple cotejo nos muestra que no ha sido así:

44. José Machado, Últimas soledades del poeta Antonio Machado. Recuerdos de su hermano José, Madrid, Ediciones de la Torre, 1999, p. 41.

45. Virgilio, Obras completas. Traducción de Bucólicas, Geórgicas y Eneida: Aurelio Espinosa Pólit, Madrid, Cátedra, 2008, p. 617

46. Julio Cejador, op. cit., tomo II, p. 197, donde se reproduce el texto del libro VI de la Eneida a partir del «ibant obscuri». 
TEXTO DE

MACHADO

«regna;"

"silvis,»

«caelum»

"Jupiter"
TEXTO DE

CEJADOR

$$
\begin{gathered}
\text { «regna:» } \\
\text { «silvis;» } \\
\text { «coelum» } \\
\text { «uppiter» }
\end{gathered}
$$

La última variante, "Jupiter», podría deberse a una errata de Machado al copiar los versos, pero hemos comprobado que hay ediciones escolares donde aparece precisamente el nombre del dios supremo escrito de esta manera. Asimismo, Machado copia este texto tres ańos antes de su carta a Cejador en 1917, por lo que creemos que aún no estaba utilizando su antología. Resulta curioso que la famosa hipálage del primer verso ("Ibant obscuri sola sub nocte»), donde el adjetivo "obscuri» correspondería por sentido lógico al sustantivo «nocte», fuera también motivo de admiración para Jorge Luis Borges, que evoca constantemente al poeta latino al final de su vida, como recuerdo indeleble de su adolescencia en Ginebra, que es cuando leyó en la escuela tales versos ${ }^{47}$. Sin embargo, en lo que respecta a Machado, no acabamos de encontrar ecos o indicios suficientes de inspiración en estos versos ${ }^{48}$, aunque la posible evocación de la Sibila en «Nevermore» (1901), poema con claros ecos de Edgar Allan Poe ya desde el mismo título, nos sugiera cierta sintonía. Recordemos que el verso de la Eneida que inicia la bajada a los infiernos de Eneas y la Sibila ("ibant obscuri sola sub nocte per umbram») consta de cuatro palabras esenciales, «obscuros», «solitaria», «noche» y «sombra», de las que tres aparecen, incluso de manera repetida, dentro del poema «Nevermore» (las cursivas son mías):

¡Amarga luz a mi rincón obscuro! (v. 2)

si obscura banda, en leve sombra suave (v. 14)

y hay más allá un plañido solitario (v. 18)

¡Espíritu de ayer! jsombra velada [...]! (v. 24)

sombra talar, en el Abril de ocaso (v. 39)

(Obras completas I, pp. 750-751)

47. Francisco García Jurado, art. cit., pp. 305-307.

48. Francisco Javier Escobar Borrego (“‘¿Soy clásico o romántico?”: de la reflexión teórica de Antonio Machado a su palabra poética», en Jordi Doménech (coordinador), Hoy es siempre todavia: curso internacional sobre Antonio Machado (Córdoba, 7-11 de noviembre de 2005), Sevilla, Ayuntamiento de Córdoba / Renacimiento, 2006, pp. 279-322, esp. p. 295, n. 39) cree encontrar referencias al verso en poemas como «Noche» $\mathrm{y}$ «Preludio» que a mí no me parecen concluyentes en absoluto, como tampoco termino de ver la relación entre la prosopopeya machadiana «la risa del campo» con la juntura, tan frecuente en las Geórgicas, de «laetus agen» (ibidem, p. 297-n. 42). "Laetus ager» no es, simplemente, «un campo feliz», sino «un campo abonado, fértil», habida cuenta del sentido primigenio que tiene «laetus» en la lengua latina, es decir, «estercolado». El concepto de felicidad en latín nace, por tanto, de una idea de fecundidad, como expresa el mismo Julio Cejador en su Diccionario etimológico-analítico latino-castellano (Madrid, Sucesores de Rivadeneira, 1926, s.v. «laetus» $\mathrm{y}$ «felo», respectivamente): «laet-us, - $a$, - um, fértil y fecundo (de tierras, plantas y animales), bien abonado (de la tierra), favorable, dichoso, alegre», $\mathrm{y}$ " felix, -ic-is, fecundo, feliz, "felices arbores Cato dixit quae fructum ferunt, infelices quae non ferunt" (Festo)". 
Precisamente, es en este poema donde aparece la enigmática expresión «sibilación escrita» (v. 21) señalada por Ángel Herrero ${ }^{49}$, con la que acaso se esté evocando a la propia Sibila de Cumas del libro VI de la Eneida:

¡Salmodias de Abril, música breve,

sibilación escrita

en el silencio de cien mares; leve

aura de ayer que túnicas agita!

("Nevermore", vv. 20-23 [Obras completas I, p. 751])

Debemos avanzar un poco, hasta la descripción del barquero Caronte, para encontrar una nueva cita del mismo libro VI, donde Machado parece aunar su obsesión por la edad y su gusto por el infierno descrito. La cita pertenece, igualmente, a 1914, y vuelve a presentar una significativa errata:

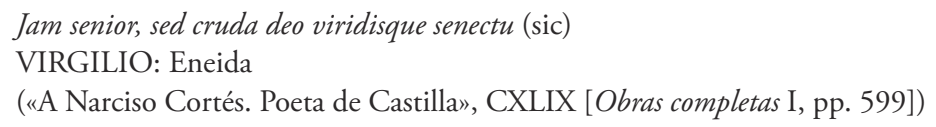

De manera precisa, la cita pertenece a Aen. 6, 304, aunque también ha quedado convertida en un lugar común para referirse, paradójicamente, a lo jóvenes que pueden ser algunos ancianos, como el mítico barquero Caronte. Si bien Machado no tuvo necesariamente que recurrir a la Eneida para saber de esta cita, es preciso tener en cuenta la predilección que sentía por el libro VI y el descenso a los infiernos ${ }^{50}$, de manera que este nuevo verso ha podido ser tomado de la misma edición escolar de la que se extrajeron también los cinco versos relativos a Eneas y la Sibila. El uso de la grafia «J» para «Jam» (en lugar de «Iam») es coherente, en este sentido, con el uso de "Jupiter» que hemos visto antes. Si comparamos esta cita con la de la égloga primera, obtenemos ahora una perspectiva distinta de la vejez, reverdecida y vivificada. Sin embargo, y al igual que ocurría con la cita de la égloga, una errata ${ }^{51}$ vuelve a presidir el texto latino, pues «senectu» debe ser «senectus», ya que concuerda con el adjetivo «viridis» («verde senectud»), referido precisamente al viejo barquero Caronte, a quien Virgilio describe de la manera siguiente:

\section{Portitor has horrendus aquas et flumina servat terribili squalore Charon, cui plurima mento canities inculta iacet; stant lumina flamma,}

49. Ángel Herrero, «La "sibilación escrita". Anagramatismo en la poesía de A. Machado", Bulletin Hispanique 98, 1996, pp. 205-209, esp. p. 215.

50. En una carta enviada a Pilar de Valderrama, fechada en agosto de 1930, Machado considera este libro VI como «el más bello de su Eneida» (Antonio Machado, Prosas dispersas (1893-1936). Introducción de Rafael Alarcón Sierra, Madrid, Páginas de Espuma, 2001, p. 640).

51. Por lo que se dice en el aparato crítico de Macrì, en todas las ediciones aparece la errata senectu (Obras completas I, p. 936, véase también a este respecto la observación y queja de Pérez Delgado, op. cit., p. 15). Sin embargo, la cita aparece correctamente en una de las prosas: «Se diría que Juan de Mairena había conocido a nuestro gran don Miguel de Unamuno, tan antideportivo, como nosotros lo conocemos: "jam senior, sed cruda deo viridisque senectus"; (Juan de Mairena, "Contra la educación física», Obras completas II, p. 1961) 
sordidus ex umeris nodo dependet amictus. Ipse ratem conto subigit velisque ministrat et ferruginea subvectat corpora cumba, iam senior, sed cruda deo viridisque senectus.

(Verg. Aen. 6, 298-304)

\section{(...) Horrendo}

el barquero que vela junto al río, Caronte, el viejo horriblemente escuálido: tendida sobre el pecho se enmaraña la luenga barba gris; innobles miran sus ojos, dos centellas, desde el hombro cuelga de un nudo su andrajoso manto.

Largo varal empuña, y con la vela hábil maniobra al trasbordar los cuerpos en el moroso esquife. Ya es anciano, mas su vejez de dios garbea airosa.

(trad. de Espinosa Pólit, op. cit., p. 619)

El poema machadiano que se ofrece bajo la cita virgiliana, "A Narciso Cortés», intenta reflejar en algún momento el contraste que plantea el verdor de la juventud («viridis») frente a la vejez («senectus»):

En tu árbol viejo anida un canto adolescente,

del ruiseñor de antaño la dulce melodía.

Poeta, que declaras arrugas en tu frente,

tu musa es la más noble: se llama Todavía.

(«A Narciso Cortés. Poeta de Castilla», CXLIX, vv. 5-8 [Obras completas I, p. 599])

Pero donde realmente se recrea el verso latino «sed cruda deo viridisque senectus» es en el conocidísimo "Soneto a Valle Inclán», a quien Machado describe inspirado en el Caronte de Virgilio ${ }^{52}$ :

Yo era en mis sueños, don Ramón, viajero del áspero camino, y tú, Caronte de ojos de llama, el fúnebre barquero de las revueltas aguas de Aqueronte.

Plúrima barba al pecho te caía. (Yo quise ver tu manquedad en vano.) Sobre la negra barca aparecía tu verde senectud de dios pagano.

Habla, dijiste, y yo: cantar quisiera loor de tu Don Juan y tu paisaje, en esta hora de verdad sincera.

Porque faltó mi voz en tu homenaje, permite que en la pálida ribera te pague en áureo verso mi barcaje.

(Obras completas I, pp. 654-655) 
Deben advertirse las afinidades textuales que encontramos en «ojos de llama» («stant lumina flamma»), "plúrima barba al pecho le caía» ("cui plurima mento ( canities inculta iacet»), y la recreación del verso latino «sed cruda deo viridisque senectus» como «tu verde senectud de dios pagano». De esta forma, si hubiera que establecer qué textos de Virgilio son los preferidos de Antonio Machado habría que decantarse, sin duda, por el libro VI de la Eneida y especialmente por el descenso de Eneas y la Sibila y por la descripción del barquero Caronte. Y precisamente, en un ejercicio de lectura anacrónica, cabe pensar cuánto de machadiano tiene ese "olmo tupido" que aparece en medio del infierno virgiliano:

In medio ramos annosaque bracchia pandit ulmus opaca, ingens, quam sedem Somnia vulgo vana tenere ferunt, foliisque sub omnibus haerent.

(Verg. Aen. 6, 282-284)

[...] Surge al medio ingente un olmo ańoso de anchas ramas, sombrío asiento de los Sueños vanos que al dorso de sus hojas se acurrucan.

(trad. de Espinosa Pólit, op. cit., p. 617)

Esta predilección por los infiernos de la Eneida lleva a Machado a asociar a Virgilio inevitablemente con Dante ya desde la primera página de Los complementarios. Regresamos ahora hasta donde habíamos encontrado por vez primera la cita de la égloga, pero en este caso para leer la segunda cita, tomada del libro XV de la Divina Comedia de Dante ${ }^{53}$ :

Siati raccomandato il mio tesoro

nel quale io vivo ancora...

(Dante. Comedia. Canto Decimoquinto.)

(Los complementarios [Obras completas II, p. 1151])

Los versos son, en concreto, el 119 y 120 del canto XV del Infierno, pero el verso 119 presenta dos modificaciones significativas, un cambio en el verbo «sieti» y la ausencia de la mayúscula en "Tesoro" ${ }^{54}$ : «sieti raccomandato il mio Tesoro». El texto está puesto en labios de Brunetto Latino, que compuso el Tesoretto, obra en verso por la que recibió la alabanza de Dante como ejemplo de poeta en lengua vulgar (cf. De vulgari eloquentia I, XIII, 1). Brunetto no fue propiamente maestro de Dante, sino un amigo mayor que le orientó en sus estudios. Ángel Crespo traduce así el pasaje:

como en él estoy vivo todavía, mi Tesoro, no más, te recomiendo. ${ }^{55}$

53. Véase el interesante comentario que hace al respecto Francisco López Estrada en Los «Primitivos» de Manuel y Antonio Machado, Madrid, Cupsa Editorial, 1977, pp. 241-242.

54. En el aparato crítico al texto de Macrì (Obras completas II, p. 1151) podemos leer: «siati. Corríjase sieti / tesoro. Corríjase Tesoro» (Obras completas II, p. 1840).

55. Dante Alighieri, Comedia. Infierno. Edición bilingüe. Traducción, prólogo y notas de 
No parece que sea casual esta conjunción de dos citas literarias que asocian, precisamente, a los poetas Virgilio y Dante. Ambos textos tienen en común una referencia temporal, «postquam» en un caso y «ancora» en el otro. El verso de Virgilio habla de la edad, mientras que los de Dante nos hablan acerca de la permanencia. Asimismo, mientras la primera cita bien podría estar referida a la circunstancia vital de Machado, la segunda se refiere a su deseo de pervivencia a través de la obra escrita. Hay un curioso poema de Machado donde podemos encontrar de nuevo unidos a Dante y a Virgilio:

¡Bajar a los infiernos como el Dante!

¡Llevar por compañero

a un poeta con nombre de Lucero!

$¡ Y$ este fulgor violeta en el diamante!

Dejad toda esperanza... Usted, primero.

$¡ O$ Oh, nunca, nunca, nunca! Usted delante.

(CLXXII. Abel Marín. Los complementarios. Cancionero Apócrifo. X [Obras completas I, p. 724])

No es difícil atisbar que, al igual que Dante, el compañero que quisiéramos llevar con nosotros al infierno es Virgilio. Según Ángel Herrero ${ }^{56}$, Virgilio, del que aquí se deja adivinar su «nombre de Lucero», aunque más que de Lucero sería de constelación («Virgo»), aparece convertido en un anagrama, sin que seamos conscientes de ello, en el verso cuarto («iy este fulGOR VIoleta en el diamante!»). Asimismo, también según Ángel Herrero, en este mismo verso aparece oculto el nombre de la Eneida ( $i \mathrm{i}$ este fulgor violeta EN El DIAmante!»). Ángel Herrero ha llamado a este fenómeno anagramático «sibilación escrita», que Antonio Machado quiso recuperar como ningún otro de los poetas espańoles. El estudio del recurso anagramático en la poesía antigua constituyó una de las obsesiones de lingüistas tan afamados como el propio Ferdinand de Saussure, precisamente durante aquellos primeros años del siglo XX. Es, cuando menos, sorprendente, observar el grado de obsesión que dominó a Saussure a la hora de buscar anagramas de nombres de dioses en la poesía de la Antigüedad. Jean Starobinski ${ }^{77}$ ha estudiado esta enigmática faceta del lingüista ginebrino, considerada por Manuel Fernández Galiano como «inquietante y casi patológica, como fuente primordial de la creación lingüística» ${ }^{58}$. Un ejemplo significativo de esta incesante búsqueda de anagramas nos lo muestra Saussure al comienzo del poema De rerum natura de Lucrecio (1, 20-22), precisamente la invocación a la diosa Venus, donde el ginebrino cree encontrar oculto el nombre propio "APRODITE»"

Ángel Crespo, Barcelona, Seix Barral, 2004.

56. Ángel Herrero, art. cit., p. 215.

57. Jean Starobinski, Las palabras bajo las palabras. La teoría de los anagramas de Ferdinand de Saussure, Barcelona, Gedisa, 1996, p. 10.

58. Para el anagrama, debe leerse la «tercera de $A B C$ » que Manuel Fernández Galiano escribiera en el número correspondiente al 7 de abril de 1988.

59. Cf. Raúl Rodríguez Ferrándiz, Semiótica del anagrama. La hipótesis anagramática de Ferdinand de Saussure, Alicante, Universidad, 1998, p. 82. 
efficis ut cupide generatim saeclA PROpagent. quae quoniam rerum naturam sola gubernas, nec sine TE quicquam DIas in luminis oras.

Si todo esto nos parece poco creíble o meramente casual, no debemos olvidar que también Virgilio recurrió al anagrama en su Eneida. Así lo vemos en lo que respecta a la palabra «Latium». Virgilio explica esta palabra mediante su relación con el verbo "LATET» («está oculto»), basada precisamente en Varrón ${ }^{60}$. Pero, no conforme con la mera explicación varroniana, el propio poeta crea a continuación un perfecto anagrama que recombina las letras de «LATIVM» para dar lugar al verbo «MALVIT» («prefirió»):

Primus ab aetherio venit Saturnus Olympo,
arma Iovis fugiens et regnis exsul ademptis.
Is genus indocile ac dispersum montibus altis
composuit legesque dedit LATIVMque vocar
MALVIT, his quoniam LATVISSET tutus
(Verg. Aen. 8, 319-323)
(...) Pero un día,
no resistiendo la agresión de Júpiter,
bajó Saturno del etéreo Olimpo
prófugo y destronado. Él a estos hombres
cerriles y en las selvas remontados
fue quien redujo a leyes el primero;
llamó su tierra "Lacio» porque en ella
latente estuvo, a salvo en su retiro.

(trad. de Espinosa Pólit, op. cit., p. 373)

Sin duda a Machado le hubiera gustado saber que su propia pasión anagramática era también compartida por su admirado poeta Virgilio. Cabría hablar aquí de una nueva y temprana sintonía entre Virgilio y Machado que, aunque menos esperable que aquellas que seńalábamos al comienzo de este trabajo, no sería menos intensa.

\section{Conclusión}

Hemos hecho un recorrido virgiliano por el cuaderno Los complementarios, que ha servido como punto de partida para llegar a otros escritos machadianos. Más allá de las sintonías vitales que podemos encontrar sin dificultad entre ambos poetas, como la percepción de la tarde, observamos que hay tres aspectos

60. «Dans un autre passage (VIII, 322 ss.), Virgile fait véritablementet concurrence à Varron, au Varron du De lingua latina aussi bien qu'à celui des Antiquités romaines. Nous y voyons le nom du Latium expliqué par le souvenir des lieux où Saturne s'était caché (latere): his quoniam latuisset tutus in oris.» (Jules Marouzeau, "Virgile linguiste», en Mélanges de Philologie, de Littérature et d'Histoire anciennes offerts à Alfred Ernout, Paris, Klincksieck, 1940, pp. 259-265, especialmente p. 260). 
que sobresalen por encima de cualquier otro, y que han configurado, al mismo tiempo, la estructura de este trabajo:

1. La edad y el tiempo, encarnados en la cita del verso 29 de la primera égloga de Virgilio. Asimismo, son significativas las dos erratas consecutivas que hemos podido rastrear en ella, la relativa a "tondendi" y la posterior de "cadet».

2. La valoración de Virgilio, más allá de la mera realidad de sus tres principales obras, como un poeta que deja traslucir una actitud vital por la que Machado siente gran empatía. Hemos descubierto, asimismo, que esta visión de Virgilio está inspirada por la lectura de Sainte-Beuve, cuyo estudio introductorio sobre el poeta latino habia traducido, precisamente, en 1914, Manuel Machado para la editorial Garnier.

3. Finalmente, hemos podido comprobar la clara predilección que Machado sentía por el libro VI de la Eneida, en particular la bajada al infierno de Eneas y la Sibila, además de la descripción del barquero Caronte. La asociación de Virgilio con Dante, el poeta que precisamente se hace acompañar por Virgilio en su propia bajada al infierno, comienza ya en la primera página de Los complementarios, donde vemos cómo la cita del verso virgiliano aparece junto a otra cita, esta vez tomada del Infierno. Esta asociación entre los dos antiguos poetas tiene lugar, asimismo, en otros lugares, incluso de manera anagramática, aspecto que presenta una nueva e inédita sintonía entre Machado y Virgilio.

No hemos pretendido en este trabajo examinar de latín a Antonio Machado, algo que en su momento hizo Julio Cejador y no precisamente sin benevolencia. Nuestro propósito ha sido analizar cómo un conocimiento precario de la lengua latina condiciona la propia percepción de su literatura y cómo este condicionamiento se convierte indudablemente en parte de la biografía de Machado. En este sentido, si bien es verdad que Antonio Machado comete erratas al citar al menos dos versos de Virgilio, tales erratas no dejan de ser parte de una vida. George Steiner puso a su autobiografía el acertado título de $E_{\text {rrata }}{ }^{61}$, pues acaso buena parte de nuestras propias estelas vitales no sea más que el fruto amasado de un sinfín de pequeños errores.

61. George Steiner, Errata. El examen de una vida, Madrid, Siruela, 1998. 